\title{
Será este o caminho? Como lidar com a imigração na era da globalização
}

Is this the way to go? Handling immigration in a global era

Est-ce le chemin? Comment appréhender l'émigration dans l'ère de globalisation

Saskia Sassen

Tradutor: João Paulo Moreira

\section{OpenEdition}

\section{Journals}

Edição electrónica

URL: http://journals.openedition.org/rccs/1230

DOI: $10.4000 /$ rccs. 1230

ISSN: 2182-7435

Editora

Centro de Estudos Sociais da Universidade de Coimbra

\section{Edição impressa}

Data de publição: 1 Dezembro 2002

Paginação: 41-54

ISSN: 0254-1106

\section{Refêrencia eletrónica}

Saskia Sassen, « Será este o caminho? Como lidar com a imigração na era da globalização », Revista Crítica de Ciências Sociais [Online], 64 | 2002, colocado online no dia 01 outubro 2012, criado a 19 abril 2019. URL : http://journals.openedition.org/rccs/1230 ; DOI : 10.4000/rccs.1230

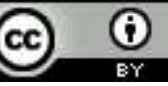




\section{Será este o caminho? Como lidar com a imigração na era da globalização}

À medida que a Europa vai fortificando as suas fronteiras, fechando-as cada vez mais à entrada de imigrantes, o tráfico ilegal de pessoas vai-se também tornando cada vez mais comum. Ao criminalizar a imigração, a Europa não só vira as costas a um sério problema moral como acaba por atingir mais profundamente quantos desesperam por fugir dos respectivos países, contribuindo ao mesmo tempo para aumentar os já enormes lucros dos traficantes responsáveis por essa actividade. O texto interroga-se sobre qual o preço que a Europa está a pagar por estas políticas, que têm tanto de míope como de insustentável.

Calcula-se em mais de 2500 o número de imigrantes que ao longo da última década terão perdido a vida ao tentar entrar clandestinamente na Europa. Um número elevado de mortes, sem dúvida, mas ainda assim um número reduzido de imigrantes para um continente com mais de 350 milhões de habitantes. Quem é esta gente a quem com tanta determinação impedimos a entrada, a ponto de a forçarmos a arriscar a vida por ela? Trata-se de uma pequeníssima minoria, também ela muito determinada, de homens, mulheres e crianças, na sua maior parte provenientes de países pobres, que de uma forma ou de outra acabarão sempre por tentar a vinda, em busca de trabalho e de refúgio. Não são criminosos, mas o resultado da nossa determinação é que estamos a alimentar um comércio que é, ele sim, criminoso. Na verdade, à medida que os países de destino têm vindo a reprimir as entradas e a semimilitarizar uma porção cada vez maior das suas fronteiras, tem-se verificado um aumento acentuado deste tráfico ilegal de pessoas.

Esta evolução levanta duas questões. Uma delas consiste no velho dilema que é a adopção de políticas criminalizadoras de algo que em si mesmo pode não constituir um acto criminoso, com vista a controlar uma situação de algum modo insustentável; com efeito, tal opção pode, por sua vez, incentivar ainda mais a prática de actividades proibidas por parte de verdadeiros 
criminosos. Um exemplo conhecido deste dilema é o caso da política de controlo da marijuana. Será que, enquanto política de controlo do uso desta substância, a criminalização da marijuana nos Estados Unidos da América - e no Reino Unido - funciona mesmo melhor do que o regime de legalidade controlada seguido na Holanda, onde a margem de lucro deixada aos eventuais traficantes é mínima e acaba por ser baixíssimo, por isso mesmo, o incentivo à expansão do uso?

A segunda questão suscitada pela referida evolução prende-se com a circunstância de as mortes das centenas de pessoas que procuram entrar na Europa nos afectarem a todos por inteiro, e não apenas as vítimas directas. O facto de as pessoas em causa não possuirem os necessários documentos de entrada permite que tanto nos círculos em que são traçadas as políticas respectivas como no âmbito dos meios de comunicação se dê delas uma imagem propícia a desculpabilizar-nos, enquanto sociedades, das suas mortes. A indocumentação parece de algum modo tornar menos humana essas mortes, reduzindo a responsabilidade que nelas eventualmente possamos ter.

O que aqui defendo é que o actual rumo das nossas políticas de imigração no sentido não apenas de um maior controlo policial e militar mas também de um crescente menosprezo pelos códigos de direitos humanos internacionalmente aceites e pelas nossa própria legislação referente às liberdades públicas está a ter como resultado a promoção do tráfico ilegal e o enfraquecimento do Estado de direito, bem como, por consequência, o próprio enfraquecimento das nossas democracias. Tais políticas estão a contribuir, de facto, para agravar um já crescente conjunto daquilo a que chamarei incentivos negativos, quer dizer, incentivos portadores de resultados negativos para sectores significativos das nossas sociedades. O tráfico ilegal e as mortes de homens, mulheres e crianças que nada têm de criminosos e que nos vêm morrer no "nosso chão" são factos que, em última análise, afectam o nosso tecido social e acabam por desvirtuar ou fragilizar o Estado de direito. Trata-se, pois, de uma realidade que acabará, a longo prazo, por nos afectar a todos nós. É certo que as vítimas imediatas são os homens e mulheres que são objecto deste tráfico, e principalmente os que morrem por sua causa. Mas seria estulto pensar que é possível permitir que tais abusos e mortes continuem a dar-se em nome da necessidade de manter o controlo, sem que isso em nada nos afecte. O crescimento do tráfico clandestino de pessoas e a adopção de políticas extremas destinadas a combater a imigração, sacrificando com isso algumas liberdades cívicas em nome das necessidades de manutenção de controlo, não são senão indícios do vasto efeito negativo a que atrás aludi. 


\section{Formas inter-relacionadas de violência}

Uma parte do desafio consiste em reconhecer a conexão estreita existente entre formas de violência que nem sempre reconhecemos como estando conectadas entre si ou como constituindo, sequer, formas de violência. O aumento acentuado da dívida pública, da pobreza e do desemprego, aliado ao encerramento de sectores da economia tradicional em todo o hemisfério sul - resultado, em boa parte, da globalização económica neoliberal deu origem a fenómenos de migração completamente novos ao mesmo tempo que veio alimentar um enorme surto de comércio ilegal de pessoas. Temos hoje provas cada vez mais evidentes de que o Fundo Monetário Internacional veio agravar estas condições do mesmo passo que trouxe uma maior prosperidade a cerca de $20 \%$ dos residentes de muitos países do Sul global. ${ }^{1}$

Ao apoiar as políticas do FMI, os nossos governos estão em certa medida a contribuir para as condições que irão estimular a emigração e o tráfico ilegal de pessoas. Além disso, ao mesmo tempo que, em parte devido a essas mesmas políticas do FMI, as economias ricas se tornam ainda mais ricas, elas tornam-se igualmente destinos mais atractivos. Tal facto, por sua vez, gera para os países de emigração fontes de divisas fortes, isto num contexto em que, por força do enfraquecimento e da frequente destruição de sectores das respectivas economias em consequência da globalização, estes países se vêem a braços com uma dívida crescente e com uma descida das receitas do Estado. Daí que estes governos também não estejam particularmente interessados em regular a emigração. Finalmente, dado que estas mesmas políticas vieram criar desigualdades e desemprego no interior das economias ricas, sucede que os mais desfavorecidos acabam também por se radicalizar, assumindo muits vezes posições políticas de extrema-direita.

A tragédia está em que aqueles que são mais afectados negativamente - aqueles que sofrem a violência em todo o Sul global e nas economias ricas e que são as vítimas de tudo isto - defrontam-se agora como inimigos no interior dos nossos países. O sentimento de hostilidade contra os imigrantes é talvez mais exacerbado entre aqueles que acabaram por ser atingidos pelas mesmas políticas que afectaram os pobres e as classes médias (mas não os $20 \%$ mais abastados) dos países em que a emigração tem origem. E, ao levantarem cada vez mais os seus muros para impedir a entrada aos imigrantes e aos refugiados, os países ricos não fazem mais do que alimentar o tráfico ilegal de pessoas e de aumentar os lucros com ele obtidos, enquanto no Sul global o desespero aumenta e no Norte global grassa o medo. Esta não é, pois, uma política sensata, mas sim um círculo vicioso.

${ }^{1}$ Para uma fundamentação deste conjunto de questões, ver Sassen, 2001 e 2002. 
A infra-estrutura técnico-institucional que deu azo aos fluxos globais de capitais e de mercadorias, de serviços e da nova classe transnacional de empresários e profissionais liberais, é a mesma infra-estrutura que permite as migrações e o tráfico ilegal. É ela também que facilita o fluxo de remessas para os países de origem dos imigrantes, o que constitui um grande incentivo para que os governos nada façam. Este novelo de factores faz aumentar a complexidade do desafio que é regular a imigração. Mas esse novelo e essa forma de complexidade estão a ir na direcção errada, pelo que há que inverter a presente dinâmica.

Sempre que as políticas inerentes à globalização correm mal, as consequências negativas abatem-se sobretudo os países do Sul global. Sucede então que, por virtude do endividamento do Estado crescente e da falta de oportunidades para os trabalhadores e para os potenciais empresários, essas políticas aumentam os incentivos à emigração e ao tráfico de emigrantes por parte tanto dos traficantes como dos próprios governos do Sul.

Com o envio das suas remessas, os emigrantes ingressam no nível macro das estratégias de desenvolvimento dos países de origem. Em muitos países, isso representa uma importantíssima fonte de reservas cambiais para o Estado. Embora os fluxos das remessas possam ser mínimos quando comparados com os enormes fluxos de capitais que diariamente cruzam os vários mercados financeiros, eles são, no entanto, frequentemente muito importantes para economias que estão a desenvolver-se ou a debater-se com dificuldades.

Em 1998, último ano sobre o qual existem disponíveis dados de âmbito abrangente, o volume de remessas enviadas pelos imigrantes para os respectivos países de origem atingiu os 70000 milhões de dólares americanos. Para se entender o verdadeiro significado deste número, há que relacioná-lo, não com o fluxo de capitais a nível global, mas sim com o PIB e com as reservas de moeda estrangeira dos países em causa. Nas Filipinas, por exemplo - um país da primeira linha no que se refere à saída de emigrantes em geral e particularmente de mulheres destinadas às indústrias recreativas -, as remessas foram a terceira maior fonte de moeda estrangeira ao longo dos últimos anos. No Bangladesh, outro país com um número significativo de emigrantes espalhados pelo Médio Oriente, pelo Japão e por diversos países da Europa, as remessas representam cerca de um terço das divisas. A exportação de trabalhadores e as remessas são meios ao dispor dos Estados para enfrentar o problema do desemprego e a dívida externa. ${ }^{2}$

\footnotetext{
${ }^{2}$ Há dois modos pelos quais os Estados colhem benefícios destas estratégias. Um deles assume um elevado grau de formalismo, sendo o outro não mais que um resultado indirecto do próprio processo migratório. Entre os exemplos mais flagrantes de um programa formal de exportação de trabalho encontram-se, actualmente, as Filipinas.
} 
Dir-se-ia que essa era uma situação já de esperar, dadas as crescentes interdependências geradas pela globalização e que, por sua vez, propiciam o tráfico ilegal de pessoas. As viagens de negócios, com o constante atravessamento das fronteiras, mais o turismo global, a Internet, e vários outros fenómenos que constituem a globalização, propiciam fluxos globais múltiplos que não estavam no horizonte de quem concebeu e promoveu a globalização económica. Tal facto obriga ao referido jogo de escolha de medidas a adoptar, um jogo difícil e dilemático, agora num contexto em que o 11 de Setembro veio agudizar ainda mais a vontade de controlar a imigração e as comunidades imigrantes residentes. $\mathrm{O}$ aumento do tráfico ilegal e a restrição das liberdades públicas não vão fazer aligeirar a necessidade de acolher um volume de imigração cada vez maior, por forma a responder às grandes mudanças demográficas que se avizinham. Seguidamente, debruçar-me-ei com algum pormenor sobre um tipo específico de fluxo, no qual se concentram muitos destes aspectos.

\section{O tráfico ilegal}

O tráfico de trabalhadores com destino ao mercado lícito e ao mercado ilegal (por exemplo o trabalho sexual não autorizado) ajuda a fazer luz sobre todo um conjunto de intersecções existentes entre o Sul global e algumas das tensões inerentes ao regime de imigração. ${ }^{3} \mathrm{O}$ tráfico constitui uma violação de vários tipos diferentes de direitos: direitos humanos, cívicos e políticos. O tráfico de pessoas parece estar essencialmente associado ao mercado do sexo, aos mercados de trabalho e à migração ilegal. Tem sido desenvolvida um vasta produção legislativa para enfrentar o problema do tráfico: tratados e cartas internacionais, resoluções da ONU, além da criação de diversos organismos e comissões. A atestar o reconhecimento da importância do tráfico clandestino está o facto de ele ter sido tratado na reunião do G8 realizada em Birmingham, em Maio de 1998. Aí, os dirigentes máximos dos oito países mais industrializados acentuaram a importância da cooperação contra o crime organizado e o tráfico clandestino de pessoas. O presidente dos EUA enviou à sua administração um conjunto de directivas com vista a reforçar e ampliar os esforços contra o tráfico de mulheres, tanto adultas como jovens. Este gesto, por sua vez, conduziria a uma iniciativa legislativa por parte do senador Paul Wellstone: a proposta de lei S.600, apresentada ao Senado em 1999. As ONGs têm desempenhado

\footnotetext{
${ }^{3}$ O tráfico implica o recrutamento forçado e/ou o transporte de pessoas dentro de um Estado ou de um Estado para outro, para fins de trabalho ou de prestação de serviços e através de formas muito variadas, todas elas envolvendo a coerção.
} 
igualmente um papel cada vez mais importante. A Coligação contra o Tráfico de Mulheres, por exemplo, conta com centros e com representantes na Austrália, no Bangladesh, na Europa, na América Latina, na África e na orla asiática do Pacífico. O Programa para a Defesa dos Direitos das Mulheres criou a Iniciativa contra o Tráfico de Pessoas, justamente para combater este comércio ilegal a nível global. De facto, este tipo de tráfico ilustra bem um dos significados da palavra interdependência no actual sistema global. Há aqui duas questões a considerar: uma delas é que a globalização veio criar novas condições e novas dinâmicas, com destaque para a procura crescente deste tipo de trabalhadores por parte das camadas profissionais de rendimento mais elevado e comummente - embora não exclusivamente associadas à globalização. ${ }^{4} \mathrm{~A}$ segunda questão é que a globalização veio permitir que certas redes e práticas de traficância até agora de âmbito nacional ou regional passassem a ter uma incidência global.

Proponho-me aqui debruçar-me sobre alguns dos dados relativos ao tráfico de mulheres, sobretudo o destinado às indústrias do sexo, bem como sobre o seu peso crescente enquanto fonte de obtenção de lucros por parte dos traficantes, sobretudo, ao que tudo indica, a partir do Sul gobal. Este facto contribui então para a importância que de um modo geral as remessas dos emigrantes - sejam eles legais ou clandestinos - assumem no saldo contabilístico de muitos dos depauperados países de origem. Sem dúvida que tanto os lucros ilegais como as receitas assim obtidas pelo Estado constituem um desincentivo a que se tomem medidas de ataque a este comércio. Enquanto forem um dos seus destinos-chave, os países do Norte global não terão como escapar às consequências dessa actividade ilícita.

Traficar emigrantes é um negócio lucrativo. Segundo um relatório da ONU, durante a década de 1990 organizações criminosas terão gerado lucros no valor de 3500 milhões de dólares por ano desta maneira (sem contar com a maior parte das mulheres destinadas à indústria do sexo). A chegada do crime organizado a esta actividade constitui um fenómeno recente, já que, no passado, ela era desenvolvida principalmente ao nível da pequena criminalidade. A CIA refere que grupos ligados ao crime organizado estão a criar em diversos países alianças estratégicas intercontinentais com recurso a redes formadas por pessoas com afinidades étnicas, uma estrutura destinada a facilitar o transporte, os contactos e a distribuição ao nível local, o fornecimento de documentação falsa, etc. A Rede para a Sobrevivência Global (Global Survival Network) deu relato público destas práticas após

\footnotetext{
${ }^{4}$ Um processo que ilustra perfeitamente este tipo de interdependência é a migração global de empregadas domésticas, amas e enfermeiras.
} 
dois anos de investigação em que recorreu à criação de uma empresa falsa para poder penetrar no comércio ilegal. As referidas redes clandestinas possibilitam também a circulação de mulheres, de uma maneira organizada, não apenas dos respectivos países de origem para os países de destino, mas inclusivamente entre países terceiros. Deste modo, os traficantes conseguem levar mulheres da Birmânia, do Laos, do Vietname e da China para a Tailândia, podendo ao mesmo tempo haver mulheres tailandesas a ser levadas para o Japão e os Estados Unidos da América.

Apesar de não existirem dados exaustivos, a informação disponível leva a crer que o tráfico de mulheres, incluindo as mulheres jovens, para a indústria do sexo é altamente lucrativa para quem o dirige. As Nações Unidas calculam que em 1998 foi de 4 milhões o número de mulheres a ser objecto deste tráfico ilegal, que terá rendido aos grupos criminosos um lucro de 7000 milhões de dólares. Neste montante estão incluídas as remessas enviadas com os ganhos das prostitutas e os pagamentos feitos aos elementos que nestes países organizam e viabilizam o negócio. No Japão, onde as chamadas indústrias recreativas são legais, os lucros atingiram, nestes últimos anos, os 4,2 biliões de ienes por ano, havendo sinais crescentes de que as mulheres que ali chegam através do tráfico clandestino constituem uma percentagem cada vez maior do total de pessoas envolvidas no trabalho sexual. Na Polónia, as autoridades policiais calculam que o traficante recebe cerca de 700 dólares por cada mulher polaca que é entregue. Na Austrália, a polícia federal calcula que o cash flow por cada duzentas prostitutas pode ascender a $\$ 900$ 000/semana. As mulheres ucranianas e russas, com grande procura no mercado do sexo, rendem aos bandos criminosos nele implicados cerca de $\$ 500$ a $\$ 1000$ por cada mulher entregue. De cada uma destas mulheres se espera que atenda, em média, 15 clientes por dia, e que renda ao gang cerca de 215000 dólares por mês.

Estima-se que ao longo dos últimos anos tenham sido traficados vários milhões de mulheres no interior e para fora tanto da Ásia como da antiga União Soviética, duas das regiões mais importantes no que diz respeito ao tráfico ilegal. Os aumentos registados no tráfico em cada uma destas regiões podem encontrar-se associados à circunstância de as mulheres estarem a ser empurradas para situações de pobreza ou a ser vendidas a agentes em resultado da pobreza dos pais ou da família. O nível elevado de desemprego nas antigas repúblicas soviéticas tem-se revelado um factor decisivo no incremento dos bandos de criminosos e do tráfico de mulheres. Em consequência do lançamento de políticas ditadas pela lei do mercado, os índices de desemprego entre as mulheres atingiram os $70 \%$ na Arménia, Rússia, Bulgária e Croácia, chegando aos $80 \%$ no caso da Ucrânia. Alguma da 
investigação levada a cabo neste domínio mostra que as carências económicas constituem a razão determinante para quem se entrega à prostituição. ${ }^{5}$

Pode bem suceder que alguns dos aspectos das políticas de imigração e da sua aplicação prática acabem por fazer com que as mulheres que já são vítimas do tráfico fiquem ainda mais vulneráveis e com poucas possibilidades de beneficiar da protecção da lei. Se não possuirem documentos legais, que é o que tende a suceder nestes casos, não serão tratadas como vítimas de abusos mas sim como violadoras da lei, uma vez que terão infringido a legislação relativa à entrada e permanência no país e a legislação laboral. Os esforços no sentido de dar resposta à entrada de imigrantes indocumentados e ao tráfico ilegal, através da criação de controlos mais apertados nas entradas das fronteiras, vão aumentar a probabilidade de as mulheres recorrerem aos traficantes, que, em alguns casos, pertencerão a organizações criminosas ligadas à indústria do sexo.

Acresce que, em muitos países, a prostituição de mulheres estrangeiras é proibida por lei. Tal facto reforça ainda mais o papel dos bandos criminosos na prostituição, ao mesmo tempo que diminui as opções de sobrevivência dessas mulheres, que de um modo geral terão um acesso limitado aos empregos disponíveis. Por outro lado, em muitos países - como é o caso da Holanda e da Suíça - a prostituição das mulheres estrangeiras é tolerada, mas já há menos tolerância para que acedam a empregos legítimos no mercado de trabalho. Segundo dados da OIM, em muitos países da União Europeia o número de prostitutas migrantes é bem mais elevado do que o das provenientes do próprio país: $75 \%$ na Alemanha, $80 \%$ no caso da cidade de Milão, na Itália, etc.

Se algumas destas mulheres têm consciência de que fazem parte de um tráfico que tem como destino a prostituição, para muitas outras as condições do seu recrutamento e a dimensão dos abusos e da sujeição que as espera só se tornam evidentes após a chegada ao país que as recebe. As condições de detenção são frequentemente extremas, próximas das de um regime de escravatura, como o são também os maus tratos a que estão sujeitas, e que incluem, além de castigos físicos, a violação e outras formas de violência sexual. São extremamente mal pagas, e, mesmo assim, o salário é-lhes muitas vezes retido. São impedidas de usar métodos de prevenção contra a sida, e vêem-se, por norma, privadas do direito a tratamento médico.

\footnotetext{
${ }^{5}$ Existe também um comércio crescente de crianças destinadas à indústria do sexo. É esse, há muito, o caso da Tailândia, mas o fenómeno está hoje presente também em diversos países da Ásia, da Europa Oriental e da América Latina.
} 
Se procuram ajuda da polícia, é provável acabarem por ser detidas, uma vez que violaram as leis referentes à imigração; se estão munidas de documentos falsos, terão que responder pela acusação de crime. ${ }^{6}$

Com o crescimento acentuado do turismo, no decurso da última década, e a sua gradual transformação num factor crucial para o desenvolvimento estratégico das cidades, regiões e até de países inteiros, o sector da recreação conheceu um desenvolvimento paralelo, acompanhado do reconhecimento de que constitui uma estratégia-chave para o desenvolvimento. Em muitos sítios, o comércio do sexo faz parte integrante da indústria da recreação, tendo conhecido, por essa razão, um crescimento similar. Há um momento em que se torna claro que o próprio comércio do sexo pode vir a tornar-se uma estratégia de desenvolvimento em regiões com índices elevados de desemprego e de pobreza e cujas autoridades governativas desesperam pela obtenção de receitas e de reservas de divisas. Quando a agricultura e a manufactura locais deixam de poder funcionar como fontes de emprego, de lucros, e de receita para o Estado, aquilo que antes não passava de uma fonte marginal de proventos, de lucro e de receitas adquire agora uma importância muito maior. A importância crescente que estes sectores vão assumindo para o desenvolvimento gera, também a um ritmo crescente, certas conexões indissociáveis. Assim, e por exemplo, sempre que o FMI ou o Banco Mundial vêem no turismo uma solução para alguns dos desafios colocados ao crescimento em muitos países pobres e concedem empréstimos para o seu desenvolvimento ou expansão, podem estar com isso a contribuir de facto para o desenvolvimento de um quadro institucional favorável à expansão da indústria da recreação e, indirectamente, do comércio do sexo.

Esta ligação estreita às estratégias de desenvolvimento é um sinal de que o tráfico de mulheres pode bem vir ainda a conhecer uma maior expansão. Essa é uma possibilidade preocupante, particularmente no contexto do número cada vez maior de mulheres para quem as opções de emprego são poucas ou nenhumas. Mas o crescimento desse número é mesmo de esperar, atendendo aos níveis elevados de desemprego e de pobreza, à retracção de um mundo laboral onde as oportunidades de trabalho estavam nos sectores mais tradicionais destas economias e à crescente carga de endividamento dos Estados, que deste modo se vêem incapazes de prestar às camadas pobres

\footnotetext{
${ }^{6}$ De acordo com a Coalition to Abolish Slavery and Trafficking, um inquérito relativo a trabalhadoras do sexo provenientes de países da Ásia apurou que muitas destas mulheres eram violadas antes de serem vendidas para a prostituição, para onde, de qualquer modo, cerca de um terço haviam sido levadas ao engano.
} 
apoio e serviços no âmbito da segurança social. Nestas condições, as mulheres envolvidas na indústria do sexo acabam por poder tornar-se também em fonte de receitas para o Estado. Em resumo, todas estas conexões são estruturais, e não propriamente resultado de eventuais propósitos conspirativos. O seu peso numa determinada economia será acrescido em função da ausência ou da diminuição de outros meios de garantir a subsistência, lucros e receitas para os trabalhadores, as empresas e o Estado, respectivamente.

\section{A crise demográfica que se avizinha no Norte}

Não obstante os esforços no sentido de evitar a entrada de imigrantes e refugiados, a verdade é que os países ricos se vêem hoje a braços com um défice demográfico cada vez maior e com populações cada vez mais envelhecidas. Segundo um importante estudo realizado pelo Instituto Demográfico Austríaco em 2001, é de prever que, a manterem-se os actuais padrões de fertilidade e de imigração, no final do século em curso a população da Europa Ocidental tenha diminuído para 75 milhões e que quase $50 \%$ dos habitantes tenham mais de 60 anos, facto que ocorrerá pela primeira vez na história da região. ${ }^{7}$ Mais ainda talvez do que os EUA - dado que acolhe um número relativamente maior de imigrantes -, a Europa defronta-se hoje em dia com algumas decisões difíceis. Onde ir buscar os trabalhadores jovens de que há necessidade para sustentar a população mais velha e realizar os trabalhos considerados menos atractivos pelos nacionais, especialmente num contexto de melhoria das habilitações académicas? Não pode dizer-se que haja uma descida do número destes empregos no seu conjunto, embora tal se verifique nalguns casos; um sector onde é provável o aumento do emprego é o dos cuidados de saúde, tanto de tipo domiciliário como institucional, para tratar do número crescente de idosos. A exportação de idosos e de certas actividades económicas é uma das opções actualmente em consideração. Contudo, existe um limite para a quantidade de idosos e de empregos de baixa remuneração que uma economia está em condições de exportar e que uma sociedade é capaz de tolerar. Daí que a imigração se perfile como podendo ser uma parte da solução.

Nos EUA, os sinais existentes evidenciam um padrão ligeiramente diferente. Prevê-se que pelos finais do século as perdas de população se fiquem pelos 34 milhões de habitantes, sendo no entanto de notar que este número representa um ponto de uma curva ascendente que só ficará completa depois

\footnotetext{
${ }^{7}$ Como é bem sabido, são vários os países europeus de primeiro plano - entre eles a Itália e a França - que cairam abaixo do nível de reprodução.
} 
do virar do século. Os dados disponíveis mostram, sem margem para dúvida, que uma componente significativa do crescimento tanto da população como da força de trabalho dos EUA ao longo das duas últimas décadas se deve aos imigrantes, sejam eles de segunda geração ou nascidos no estrangeiro. Em ambos os casos, os imigrantes constituem, em relação aos valores do crescimento, uma percentagem maior do que aquela que lhes corresponde em termos tanto da população em geral como do total da força de trabalho.

Apesar de tudo isto, as actuais formas de procedimento dos países do Norte global não são de molde a prepará-los para enfrentar este quadro futuro. Assim, preocupam-se com construir muros para manter afastados os que para lá desejam imigrar. Ao mesmo tempo, num período de crescentes fluxos de refugiados, o Alto Comissariado das Nações Unidas para os Refugiados defronta-se com uma carência de fundos ainda mais grave do que é habitual. Em face de uma procura efectiva de trabalhadores - e inclusivamente de famílias - imigrantes por razões demográficas, as opções políticas subjacentes a estas duas formas de reagir irão, provavelmente, ter repercussões negativas para a Europa. Ambas concebem tacitamente o imigrante e o refugiado como um sujeito negativo e indesejável, colocando desse modo grandes entraves à sua integração. Enfim, pode dizer-se que, dada a disposição de contratar mão-de-obra imigrante por parte de muitas empresas e famílias, pelas mais diversas razões, é de esperar que as actuais políticas restritivas e as representações baseadas em preconceitos raciais sobre o imigrante e o refugiado venham alimentar o já crescente tráfico ilegal de pessoas.

\section{Conclusão: A necessidade de uma política de imigração mais esclarecida}

A grande questão, sem dúvida incontornável, com que se defrontam as sociedades em que prevalece o Estado de direito, é saber se as políticas que brutalizam as pessoas - independentemente da respectiva nacionalidade e que promovem o lucro obtido por actividade criminosa relacionada com o tráfico humano são desejáveis e até sustentáveis se queremos continuar a basear os nossos sistemas no Estado de direito pelo qual os nossos antepassados tanto lutaram e derramaram o seu sangue.

Permitir este tipo de brutalização e de criminalidade é um preço demasiado elevado a pagar pela manutenção do controlo das fronteiras, um preço que mais cedo ou mais tarde há-de começar a desgastar o próprio tecido do Estado e da sociedade civil.

Já amplamente documentados, os riscos para as nossas sociedades e para nós próprios enquanto cidadãos encontram-se bem patentes naquilo que 
está a acontecer nos EUA. Os acontecimentos do 11 de Setembro e as subsequentes restrições às liberdades públicas de determinados grupos de imigração estão, aí, a desgastar, e há quem pense que a enfraquecer, o Estado de direito tal como afecta todos os residentes desse país. O governo norte-americano está a chamar a si uma autoridade cada vez mais forte a fim de tratar directamente, por via extrajudicial, questões que antes eram da competência do poder judiciário ou que não eram consideradas matéria em que o governo devesse interferir. Ao fazê-lo, o governo dos EUA está a violar os direitos básicos, não apenas das pessoas que identificou como eventualmente perigosas, mas de todos os seus cidadãos, quer sejam suspeitos ou não.

Será que existem maneiras de regular o fluxo de gente que demanda as nossas sociedades que, em vez de enfraquecer o nosso tecido social, contribuam para o reforçar? Por certo que não é esse o caso dos constantes incidentes de pessoas que morrem às mãos dos traficantes ao tentarem a imigração clandestina. Pela frequência com que ocorrem, arriscamo-nos a que tais casos acabem por gerar a indiferença e por fomentar uma aceitação generalizada dessas mortes por parte de nós próprios e dos nossos filhos, tudo em nome da manutenção do controlo sobre a entrada no nosso espaço.

Estamos a pagar um preço não só pelos que morrem no nosso solo, mas também por quantos são contrabandeados com vida para dentro dos nossos países. O preço que pagamos por permitir essa forma de abuso e maus-tratos que é o contrabando humano acaba por ser bem mais elevado do que o "preço" que pagamos por acolher e incorporar no nosso seio estas pessoas que mais não querem do que uma oportunidade de trabalho - trabalho que efectivamente realizam. Na verdade, muita da investigação empreendida sobre o tema sugere que de facto ganhamos com a presença destes imigrantes. Assim, e por exemplo, 17\% dos empresários londrinos pertencem a comunidades étnicas, o que constitui uma percentagem mais alta do que o respectivo peso relativo entre o resto da população.

A manutenção de políticas que tornam possível a brutalização daqueles que se lançam na aventura da migração e a acumulação de lucros por parte dos traficantes é um cancro profundamente enraízado nos nossos Estados e nas nossas sociedades. É esse o preço que pagamos pela criminalização de imigrantes indocumentados e, de uma maneira mais geral, pelo recurso ao policiamento e à militarização enquanto forma de regular a imigração. O exemplo dos EUA ilustra, em certa medida, isso mesmo. Em nome de uma maior eficácia no controlo, a nova Lei da Imigração deste país, apro- 
vada em 1996, reforçou o policiamento atenuando o controlo jurisdicional sobre as acções policiais que têm por alvo a imigração. Um aspecto crucial, em tudo isto, é o do objecto concreto deste alargamento da vigilância policial: o alvo não são criminosos já conhecidos, nem empresas suspeitas de violação da legislação ambiental, nem os traficantes de droga, mas sim todo um sector da população; nem sequer pessoas individualmente referenciadas, mas uma faixa bastante larga da sociedade e que abrange homens, mulheres e crianças.

Esta tensão - uma tensão entre, por um lado, o reforço da resposta policial para regular a imigração e, por outro lado, o reforço dos direitos civis e humanos e o sentimento de mobilização cívica associado ao fortalecimento da sociedade civil - tem as suas consequências. Mais cedo ou mais tarde, esta tendência para um maior policiamento irá enredar-se nessa teia em vias de expansão que são os direitos civis e humanos. E nestes direitos hão-de estar incluídos os direitos dos cidadãos. Liberto do travão da supervisão civil, o policiamento pode facilmente acabar por violar esses direitos e interferir com o bom funcionamento da sociedade civil.

Se o meu filho decidisse que ia escrever ele o tal grande romance americano, e para isso fosse viver temporariamente entre trabalhadores agrícolas ou nas fabriquetas da indústria do vestuário, e se houvesse uma rusga do Serviço de Imigração e Naturalização (INS), é muito provável que fosse incluido entre os suspeitos, uma vez que sei que não traria consigo o seu passaporte americano. Pior ainda, se se encontrasse num grupo de trabalhadores agrícolas da Califórnia a fugir da polícia do INS e se visse impelido a atirar-se aos canais de água, como sucedeu já por diversas vezes ao longo dos últimos anos, é bem provável que, como outros, acabasse por morrer afogado. O mais dramático dos relatos que temos sobre este tipo de incidentes refere que as águas tumultuosas terão, na altura, parecido menos ameaçadoras do que a polícia do INS, com as suas armas e aos gritos, e que a verdade é que estes trabalhadores agrícolas terão sido aterrorizados a ponto de se lançarem às águas e de se afogarem. Após a lei de 1996, muitas destas acções do INS poderão furtar-se aos mecanismos de supervisão e a uma eventual responsabilização perante os tribunais, se se considerar que as pessoas perseguidas eram apenas suspeitas de estar indocumentadas. Mais tarde ou mais cedo, o policiamento abusivo ou excessivo e o abrandamento do controlo jurisdicional sobre tais acções irão comprometer a aspiração à construção plena do Estado de direito, componente profundíssima da nossa herança colectiva e da nossa realidade vivida. Mais tarde ou mais cedo, este tipo de acção policial acabará por nos afectar a nós também, cidadãos documentados. Precisamos, por isso, de encontrar outros meios 
de regular o acesso às fronteiras, porque presentemente o que sucede é que estamos a reforçar modos de controlo que comportam um custo elevado, contabilizado em mortes de imigrantes e em perda para o Estado de direito.

Tradução de

João Paulo Moreira

\section{Referências Bibliográficas}

Sassen, Saskia (2001), The Global City. Princeton: Princeton UP (nova edição, actualizada).

Sassen, Saskia (2002), "Governance Hotspots in the Post-September 11 World", in Ken Booth; Tim Dunne (orgs.), Worlds in Collision. Terror and the Future of Global Order. Basingstoke: Palgrave. 